\title{
STEADY STATE AND DYNAMIC EVALUATION OF ELECTRICAL SHAFT SYSTEM
}

\author{
Sid Ali Fellag
}

\begin{abstract}
In this paper a steady state and dynamic assessment of electrical shaft with common resistance are performed. New steady state formulae that take into account the stator resistances are developed. The system is presented in a full version similar to individual induction machine in the $d q$ frame but without stator resistance simplifications. It is found that the stator resistance is worth-taking into account.
\end{abstract}

K e y w or d s: common resistance, stator resistance, induction motor, synchronization, electrical shaft

\author{
Nomenclature \\ $U_{a}, U_{b}, U_{c}-$ Three phase balanced main sources. \\ $U_{s 1}, U_{s 2}$ - Stator voltages of the first and second mo- \\ tors respectively. \\ $R \quad-$ Common resistance. \\ $R_{s}, R_{r} \quad$ - Stator and rotor per phase resistance. \\ $L s, L r-\quad$ - Self-inductance of stator and rotor phases. \\ $L_{m} \quad-$ Mutual inductance between stator and ro- \\ tor phases. \\ $\theta_{1}, \theta_{2} \quad$ - Instantaneous rotor angles of first and sec- \\ ond motors. \\ $w_{1}, w_{2} \quad-$ Speed of first and second motors. \\ $p \quad-$ Differentiation operator. \\ $T_{s_{1}}, T_{s_{2}} \quad$ - Load torque of first and second machines. \\ $J \quad-$ Rotor inertia. \\ $\Psi \quad-$ Flux linkage \\ $\omega_{0} \quad-$ Speed of synchronism.
}

\section{INTRODUCTION}

The use of multiple motor drives has been mentioned in many published works [1-14] and [16]. For electrical shaft ESh which is a classical multiple motor system with two induction motors [1-8], all the studies done before have investigated the system with a lot of simplifications. In the steady state and dynamic behaviours there was always an ignoring of stator resistances SR [1-8]. Indeed this ignoring may not lead to big errors when dealing with individual IM machines especially in the medium-high power range. However, in ESh, it leads to big mistakes for this same range and may cause a loss of synchronization. The essential feature that the system was built for. An assessment of ESh behaviour may be done by both, classical steady state and modern transient regime modelling. Both approaches are necessary and complete each other.
In this study a mathematical tool to investigate the system with SR by building angular characteristics that assess the capability of the synchronization [1-4], [6-8] and [16] was developed. The evaluation of the steady state can be done classically using the known steady state torque formulae of an individual IM known in IM classical theory [3],[6] and 15]. However, ESh has been investigated earlier only when $\mathrm{SR}$ is ignored ${ }^{1}$, so the new formulae that can take into account SR were proposed.

The dynamic model will rely, instead of small-signal approach used in previous works [5], [6] and [8], on the full mathematical equations as for an individual IM using the diphase $d q$ transformation. Relying on this model, the importance of SR is clearly shown.

\section{PRINCIPLE OF FUNCTIONING}

The principle electrical scheme of ESh is shown in Fig. 1. It is consisted from two induction motors sharing a common resistance, and assumed to have the same electrical parameters. The resistance in it plays a key role in allowing a power exchange between motors.

In case when both motors carry the same load they will both rotate on the same speed; their rotors, having the same electro motion force, would occupy the same angle positions. But in case of different load carrying, this would yield a circulation of currents between the two rotors. The currents interacting with machine magnetic fields would create the so-called synchronizing torques which are directed in such a way striving to eliminate the cause of their creation, and so do return the rotors to equal angle positions.

\footnotetext{
${ }^{1}$ In the steady state analysis to consider the influence of SR a complicated circle diagram method was used [3], [6] and [8]. The dynamics had relied on the small signals approaches and SR was not taken into account [5], [6] and [8].
}

* Faculty of electrical Engineering, Department of Electrotechnics, University of Technology of Tizi Ouzou, Tizi-Ouzou 15000, Algéria, eedis2001@yahoo.fr 


\section{ELECTRICAL SHAFT STEADY STATE MODEL}

The equivalent circuit of ESh is, according to [1-4], shown in Fig. 2. Here: $r_{1}, x_{1}-$ are active resistance and reactance of stator windings; $r_{2}, x_{2}$ - are active resistance and reactance of rotor windings; $x_{\mu}$ - is the reactance of motor magnetic circuit; $R^{\prime}$ - is common active resistance of ESh; $\alpha_{1}$ - is the electrical rotor position of the first motor; $\alpha_{2}-$ is position of the second. $U_{1}, U_{2}$ - are the complex voltages of the first and the second machine respectively. All rotor circuit parameters are referred to the stator.

In order to get ESh torque formulae in steady state we will use the torque expression of an individual IM with SR brought in [6] as

$$
M=\frac{3}{\omega_{0}}\left(\frac{U}{2 \sigma}\left[I_{2}+I_{2}^{*}\right]-\left|\frac{I_{2}}{\sigma}\right|^{2} r_{1}\right)
$$

where $I_{2}$ - is the rotor complex current and $I_{2}^{*}-$ is its complex conjugate, $\sigma=1+\frac{\xi_{1}}{\xi_{\mu}}-$ is the Hopkinson coefficient (Blondel in English literature), [6].

By putting the complex rotor current

$$
I_{2}=\frac{U}{r_{1}+\frac{r_{2} \sigma}{s}+j x_{k}}
$$

of an individual IM into (1) it is easy to convince oneself that it would lead to the known torque formulae of an IM with SR.

Let us denote according to Fig. 2

$$
\begin{aligned}
& Z_{1}=r_{1}+j\left(x_{\mu}+x_{1}\right) \\
& Z_{2}=\frac{r_{2}}{s}+j\left(x_{\mu}+x_{2}\right), \quad Z=\frac{R}{s}
\end{aligned}
$$

From the equivalent circuit and referring to the first machine we can write

$$
U=I_{11} Z_{1}-I_{21}\left(j x_{\mu}\right)
$$

and equally

$$
I_{11}\left(j x_{\mu}\right) e^{j \alpha_{1}}-I_{21} Z_{2} e^{j \alpha_{1}}=Z\left(I_{21} e^{j \alpha_{1}}+I_{22} e^{j \alpha_{2}}\right)
$$

(3) is the critic torque of an individual IM without SR and Considering $I_{11}$ from (2) we re-write (3) as

$$
\begin{array}{r}
U\left(j x_{\mu}\right) e^{j \alpha_{1}}-\left(x_{\mu}^{2}-Z_{1} Z_{2}\right) I_{21} e^{j \alpha_{1}} \\
=Z Z_{1}\left(I_{21} e^{j \alpha_{1}}+I_{22} e^{j \alpha_{2}}\right)
\end{array}
$$

and in analogue for the second machine

$$
\begin{array}{r}
U\left(j x_{\mu}\right) e^{j \alpha_{2}}-\left(x_{\mu}^{2}-Z_{1} Z_{2}\right) I_{22} e^{j \alpha_{2}} \\
=Z Z_{1}\left(I_{22} e^{j \alpha_{2}}+I_{22} e^{j \alpha_{1}}\right)
\end{array}
$$

Adding (3) to (4) after necessary arrangement we get

$$
I_{22} e^{j \alpha_{2}}+I_{21} e^{j \alpha_{1}}=\frac{U\left(j x_{\mu}\right)\left(e^{j \alpha_{2}}+e^{j \alpha_{1}}\right)}{x_{\mu}^{2}-Z_{1} Z_{2}+2 Z_{1} Z_{2}}
$$

now adding (5) to (3) after some manipulations the current of the first machine, with $\alpha=\alpha_{1}=\alpha_{2}$ will be

$$
I_{21}=U\left(j x_{\mu}\right)\left[\frac{x_{\mu}^{2}+Z_{1}\left(Z_{2}+Z\left(2-\left(1+e^{j \alpha}\right)\right)\right)}{\left(x_{\mu}^{2}+Z_{1} Z_{2}\right)\left(x_{\mu}^{2}+Z_{1}\left(Z_{2}+2 Z\right)\right)}\right]
$$

Considering $Z_{1} \approx j x_{\mu} \sigma$ as we can neglect $r_{1}$ with respect to $x_{\mu}+x_{1}$, if we write

$$
\left(x_{\mu}^{2}+Z_{1} Z_{2}\right)=Z_{1}\left(Z_{2}-j x_{\mu}\right)+j x_{\mu}\left(Z_{1}-j x_{\mu}\right)
$$

we can find

$$
\begin{aligned}
\left(x_{\mu}^{2}+Z_{1} Z_{2}\right) & =j x_{\mu} Z_{k} \\
\text { with } \quad Z_{k} & =\left(r_{1}+\frac{\sigma r_{2}}{s}\right)+j x_{k} \\
x_{k} & =x_{1}+\sigma x_{2}
\end{aligned}
$$

so, taking (8) into account we get for the complex currents of respective machines

$$
I_{21}=I_{22} \frac{U}{2}\left[\frac{\left(1-e^{j \alpha}\right)}{Z_{k}}+\frac{\left.1+e^{j \alpha}\right)}{\left(Z_{k}+2 \sigma Z\right)}\right]
$$

putting this into (1), and denoting as shown below, we get

$$
\begin{aligned}
M^{*} & =\frac{M}{M_{m}}=\left[\frac{\frac{s_{m}}{s}(1-\cos \alpha)}{\left(\frac{s_{m}}{\sigma_{1}}+\frac{s_{m}}{s}\right)^{2}+1}+\frac{\frac{s_{m}}{s}(1+\cos \alpha)}{\left(\frac{s_{m}}{\sigma_{1}}+\frac{s_{m}}{s^{\prime}}\right)^{2}+1} \pm\right. \\
& \pm \sin (\alpha) \frac{\left(\frac{s_{m}^{\prime}}{s}-\frac{s_{m}}{s}\right)\left[\frac{s_{m}^{\prime}}{s}+\frac{s_{m}}{s}+4 \frac{s_{m}}{\sigma_{1}}\right]}{\left[\left(\frac{s_{m}}{\sigma_{1}}+\frac{s_{m}}{s}\right)^{2}+1\right]\left[\left(\frac{s_{m}}{\sigma_{1}}+\frac{s_{m}^{\prime}}{s}\right)^{2}+1\right]}
\end{aligned}
$$

where

$$
\begin{array}{r}
\frac{s_{m}^{\prime}}{s}=\frac{s_{m}}{s}+\frac{2 R \sigma}{s x_{k}}=\frac{s_{m}}{s}\left(1+\frac{2 R}{r_{2}}\right) \\
\frac{2 R \sigma}{s x_{k}}=\frac{s_{m}^{\prime}}{s}-\frac{s_{m}}{s}, \quad s_{m}=\frac{r_{2} \sigma}{x_{k}}
\end{array}
$$

and where

$$
M_{m}=\frac{3 U^{2}}{2 \sigma \omega_{0} x_{k}}, \quad \sigma_{1}=\sigma \frac{r_{1}}{r_{2}}
$$
newly defined coefficient.

Putting $r_{1}=0$ with simple arrangement we will return to the known expressions got earlier in [3-4], [6] and [8] when SR was neglected.

$$
M^{*}=\frac{(1-\cos \alpha) \pm \frac{s}{s_{m}} \sin \alpha}{\frac{s_{m}}{s}+\frac{s}{s_{m}}}+\frac{(1+\cos \alpha) \pm \frac{s}{s_{m}^{\prime}} \sin \alpha}{\frac{s_{m}}{s}+\frac{s}{s_{m}^{\prime}}}
$$

Using (10) and (11) we have plotted Fig. 3 to show the importance of SR. Such importance will be more obvious when modelling the transient behaviour of the system. 


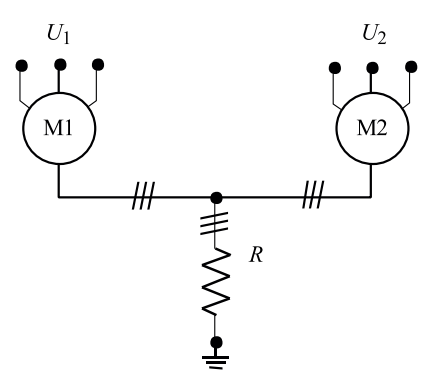

Fig. 1. Electrical scheme of electrical shaft

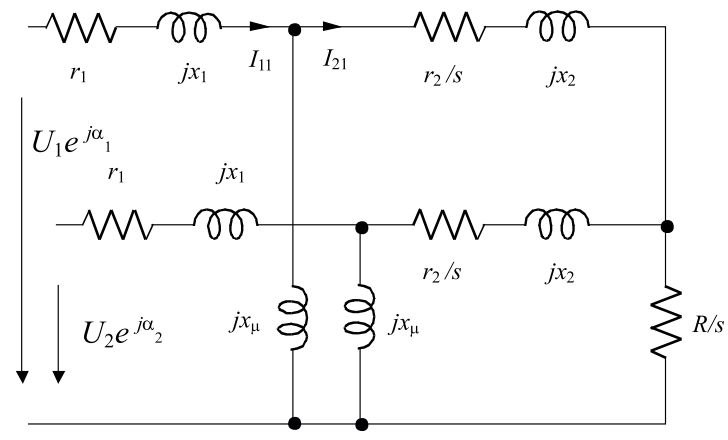

Fig. 2. Equivalent electrical scheme)

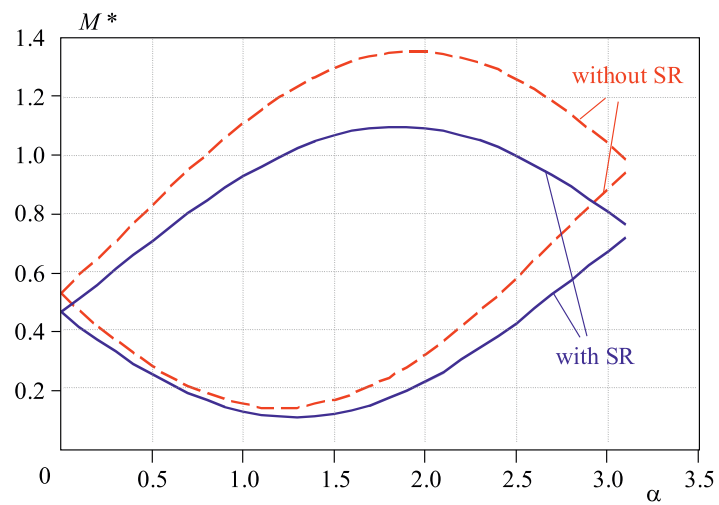

Fig. 3. Angular characteristics: 1 - dashed - without SR, 2 - bold with SR

\section{ELECTRICAL SHAFT DYNAMIC MODEL}

The overall electrical scheme of ESh shown is composed from two induction machines that share in common resistance.

An induction machine in general case can be expressed by the known six equations

$$
\begin{aligned}
U_{s a} & =i_{s a} R_{s}+\frac{\mathrm{d} \Psi_{s a}}{\mathrm{~d} t}, \\
U_{s b} & =i_{s b} R_{s}+\frac{\mathrm{d} \Psi_{s b}}{\mathrm{~d} t}, \\
U_{s c} & =i_{s c} R_{s}+\frac{\mathrm{d} \Psi_{s c}}{\mathrm{~d} t}, \\
-U_{r a} & =i_{r a} R_{r}+\frac{\mathrm{d} \Psi_{r a}}{\mathrm{~d} t} .
\end{aligned}
$$

$$
\begin{aligned}
& -U_{r b}=i_{r b} R_{r}+\frac{\mathrm{d} \Psi_{r b}}{\mathrm{~d} t} . \\
& -U_{r c}=i_{r c} R_{r}+\frac{\mathrm{d} \Psi_{r c}}{\mathrm{~d} t} .
\end{aligned}
$$

in terms of ESh it can be expressed for The first machine as

$$
\begin{aligned}
U_{s_{1} a} & =i_{s_{1} a} R_{s_{1}}+\frac{\mathrm{d} \Psi_{s_{1 a}}}{\mathrm{~d} t} \\
U_{s_{1} b} & =i_{s_{1} b} R_{s_{1}}+\frac{\mathrm{d} \Psi_{s_{1 b}}}{\mathrm{~d} t} \\
U_{s_{1} c} & =i_{s_{1} a} R_{s_{1}}+\frac{\mathrm{d} \Psi_{s_{1 a}}}{\mathrm{~d} t} \\
-U_{r_{1} a} & =i_{r_{1} a}\left(R_{r_{1}}+R\right)+i_{r_{2} a} R+\frac{\mathrm{d} \Psi_{r_{1} a}}{\mathrm{~d} t} \\
-U_{r_{1} b} & =i_{r_{1} b}\left(R_{r_{1}}+R\right)+i_{r_{2} b} R+\frac{\mathrm{d} \Psi_{r_{1} b}}{\mathrm{~d} t} \\
-U_{r_{1} c} & =i_{r_{1} c}\left(R_{r_{1}}+R\right)+i_{r_{2} c} R+\frac{\mathrm{d} \Psi_{r_{1} c}}{\mathrm{~d} t} .
\end{aligned}
$$

The second machine can be expressed by the same equations but with index " 2 " instead of "1".

According to the matrix theory, stator and rotor equations can be expressed each by only one matrix vector summarized in the following writing

$$
\begin{array}{r}
{\left[U_{s_{1(2)} a b c}, U_{r_{1(2)} a b c}\right]=\left[\left[i_{s_{1(2)} a b c}\right]\left[R_{s}\right]+p\left[\psi_{s_{1(2)} a b c}\right],\right.} \\
\left.\left[i_{r_{1(2)} a b c}\right]\left[R_{r}+R\right]+\left[i_{r_{2(1)} a b c}\right][R]+p\left[\psi_{r_{1(2)} a b c}\right]\right]
\end{array}
$$

or in detail which gives the following form

$$
\begin{aligned}
{\left[\begin{array}{c}
{\left[U_{s_{1} a b c}\right]} \\
-\left[U_{r_{1} a b c}\right]
\end{array}\right]=} & {\left[\begin{array}{c}
{\left[i_{s_{1} a b c}\right]} \\
-\left[i_{r_{1} a b c}\right]
\end{array}\right]\left[\begin{array}{cc}
{\left[R_{s}\right]} & {[0]} \\
{[0]} & {\left[R_{r}+R\right]}
\end{array}\right]+} \\
& {\left[\begin{array}{c}
{[0]} \\
{\left[i_{r_{2} a b c}\right]}
\end{array}\right]\left[\begin{array}{c}
{[0]} \\
{[R]}
\end{array}\right]+p\left[\begin{array}{cc}
{\left[\Psi_{s_{1} a b c}\right.} & {[0]} \\
{[0]} & {\left[\Psi_{r_{1} a b c}\right]}
\end{array}\right] }
\end{aligned}
$$

$$
\begin{aligned}
{\left[\begin{array}{c}
{\left[U_{s_{2} a b c}\right]} \\
-\left[U_{r_{2} a b c}\right]
\end{array}\right]=} & {\left[\begin{array}{c}
{\left[i_{s_{2} a b c}\right]} \\
-\left[i_{r_{2} a b c}\right]
\end{array}\right]\left[\begin{array}{cc}
{\left[R_{s}\right]} & {[0]} \\
{[0]} & {\left[R_{r}+R\right]}
\end{array}\right]+} \\
& {\left[\begin{array}{c}
{[0]} \\
{\left[i_{r_{1} a b c}\right]}
\end{array}\right]\left[\begin{array}{c}
{[0]} \\
{[R]}
\end{array}\right]+p\left[\begin{array}{cc}
{\left[\Psi_{s_{2} a b c}\right.} & {[0]} \\
{[0]} & {\left[\Psi_{r_{2} a b c}\right]}
\end{array}\right] }
\end{aligned}
$$

with

$$
\left[\begin{array}{lll}
A_{s(r) a b c}
\end{array}\right]=\left[\begin{array}{lll}
A_{s(r) a} & A_{s(r) b} & A_{s(r) c}
\end{array}\right]^{\top}
$$

( $A$ means any of the vectors $U, \Psi$ or $i$ ).

$$
\begin{gathered}
{\left[R_{s}\right]=\left[\begin{array}{ccc}
R_{s_{1(2)}} & 0 & 0 \\
0 & R_{s_{1(2)}} & 0 \\
0 & 0 & R_{s_{1(2)}}
\end{array}\right],[R]=\left[\begin{array}{ccc}
R & 0 & 0 \\
0 & R & 0 \\
0 & 0 & R
\end{array}\right]} \\
{\left[R_{r}+R\right]=\left[\begin{array}{rrr}
R_{r_{1(2)}}+R & 0 & 0 \\
0 & R_{r_{1(2)}}+R & 0 \\
0 & 0 & R_{r_{1(2)}}+R
\end{array}\right]}
\end{gathered}
$$

A more simple description is obtained when the system (13) converted to the diphase $d q$ frame and adopting the 

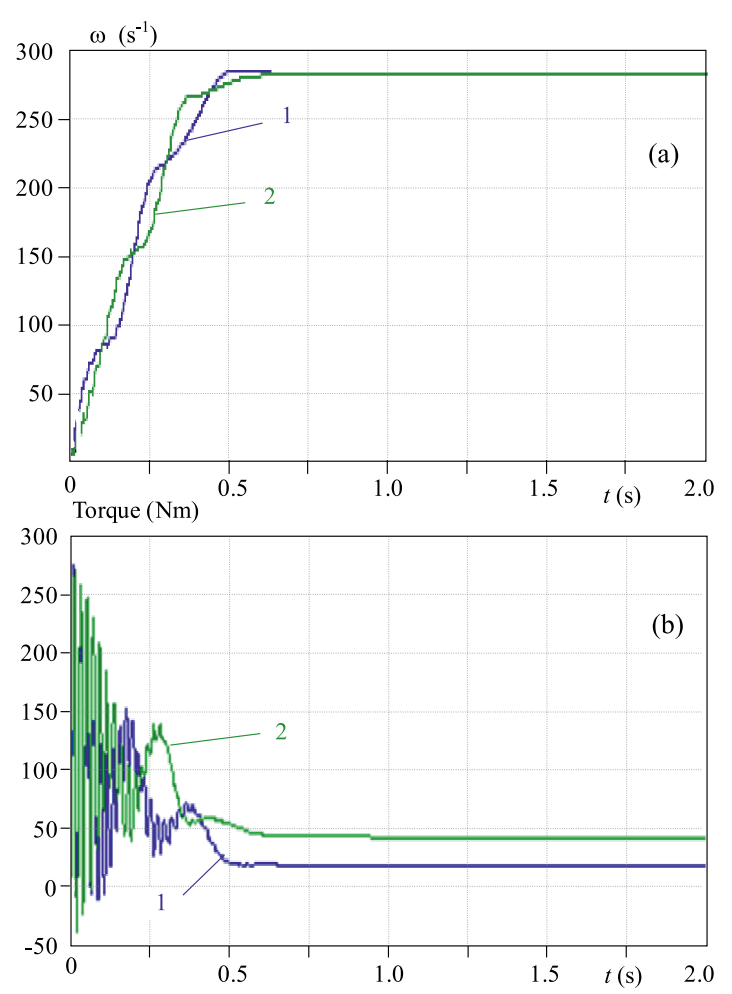

Fig. 4. (a) - Speed responses (stators resistance increasing) "synchronization lost", (b) - Torque responses (synchronization lost)

simplification hypothesis: core losses, saturation effects and space harmonics are neglected along with rotor and stator symmetry [2] and [15] also the parameters of the two machines are set as identical. Having this in mind, the system after conversion will be as

$$
\begin{aligned}
& {\left[\begin{array}{l}
{\left[U_{s_{1} d q}\right]} \\
{\left[U_{r_{1} d q}\right]}
\end{array}\right]=\left[\begin{array}{l}
{\left[i_{s_{1} d q}\right]} \\
{\left[i_{r_{1} d q}\right]}
\end{array}\right]\left[\begin{array}{cc}
{\left[R_{s}\right]} & {[0]} \\
{[0]} & {\left[R_{r}+R\right]}
\end{array}\right]+\left[\begin{array}{c}
{[0]} \\
{\left[i_{r_{2} d q}\right]}
\end{array}\right]\left[\begin{array}{l}
{[0]} \\
{[R]}
\end{array}\right]} \\
& +p\left[\begin{array}{cc}
{\left[\Psi_{s_{1} d q}\right]} & {[0]} \\
{[0]\left[\Psi_{r_{1} d q}\right]+p \theta_{1}}
\end{array}\right]\left[\begin{array}{c}
{\left[\Psi_{s_{1} q d}\right]} \\
{[0]}
\end{array}\right], \\
& {\left[\begin{array}{l}
{\left[U_{s_{2} d q}\right]} \\
{\left[U_{r_{2} d q}\right]}
\end{array}\right]=\left[\begin{array}{l}
{\left[i_{s_{2} d q}\right]} \\
{\left[i_{r_{2} d q}\right]}
\end{array}\right]\left[\begin{array}{cc}
{\left[R_{s}\right]} & {[0]} \\
{[0]} & {\left[R_{r}+R\right]}
\end{array}\right]+\left[\begin{array}{c}
{[0]} \\
{\left[i_{r_{1} d q}\right]}
\end{array}\right]\left[\begin{array}{l}
{[0]} \\
{[R]}
\end{array}\right]} \\
& +p\left[\begin{array}{cc}
{\left[\Psi_{s_{2} d q}\right]} & {[0]} \\
{[0]} & {\left[\Psi_{r_{2} d q}\right]+p \theta_{2}}
\end{array}\right]\left[\begin{array}{c}
{\left[\Psi_{s_{2} q d}\right]} \\
{[0]}
\end{array}\right]
\end{aligned}
$$

with

$$
\begin{gathered}
{\left[R_{s}\right]=\left[\begin{array}{cc}
R_{s} & 0 \\
0 & R_{s}
\end{array}\right],[R]=\left[\begin{array}{cc}
R & 0 \\
0 & R
\end{array}\right],} \\
{\left[R_{r}+R\right]=\left[\begin{array}{cc}
R_{r}+R & 0 \\
0 & R_{r}+R
\end{array}\right] .}
\end{gathered}
$$

The flux vectors can be given by their known, in induction machine theory, expressions [2]

$$
\begin{aligned}
& {\left[\Psi_{s d q}\right]=\left[i_{s d q}\right]\left[L_{s}\right]+\left[i_{r d q}\right]\left[L_{m}\right]} \\
& {\left[\Psi_{r d q}\right]=\left[i_{r d q}\right]\left[L_{r}\right]+\left[i_{s d q}\right]\left[L_{m}\right]}
\end{aligned}
$$
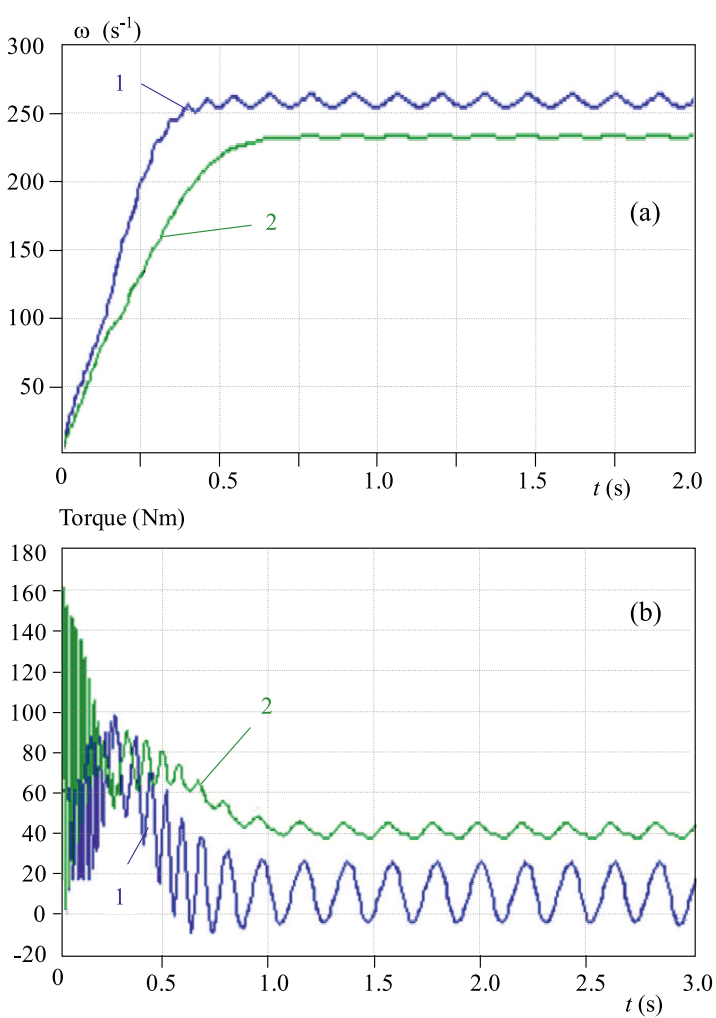

Fig. 5. (a) - Successful synchronization (equal rotor angles at start), (b) - Synchronization lost (deferent rotor angles at start)

Being lengthy but well known in IM diphase theory and published in many previous works - see for example [2], [15] for detail — the steps leading to (13) were avoided to be brought here. Putting (3) in (2) and having a short circuit rotor for both machines $\left(i e U_{r}=0\right)$ the mathematical model of ESh in a compact matrix form will be as

$$
\begin{aligned}
& \left\|\begin{array}{l}
U_{s_{1} d} \\
U_{s_{2} d} \\
U_{s_{1} q}
\end{array}\right\| \quad \begin{array}{cccc}
R_{s}+p L_{s} & 0 & w_{1} L_{s} & 0 \\
0 & R_{s}+p L_{s} & 0 & w_{2} L_{s} \\
-w_{1} L_{s} & 0 & R_{s}+p L_{s} & 0
\end{array} \\
& U_{s_{2} q}=\begin{array}{cccc}
0 & -w_{1} L_{s} & 0 & R_{s}+p L_{s} \\
p L_{m} & 0 & 0
\end{array} \\
& \begin{array}{ccccc}
0 & = \\
0
\end{array} \quad \begin{array}{cccc}
0 & 0 & 0 & 0
\end{array} \\
& \begin{array}{l|llll}
0 & 0 & p L_{m} & 0 & 0
\end{array} \\
& \begin{array}{l|llll}
0 & 0 & p L_{m} & 0
\end{array} \\
& \begin{array}{l|lllll}
0 & 0 & 0 & 0 & p L_{m}
\end{array} \\
& \begin{array}{cccc}
p L_{m} & 0 & w_{1} L_{m} & 0 \\
0 & p L_{m} & 0 & w_{2} L_{m} \\
-w_{1} L_{m} & 0 & p L_{m} & 0 \\
0 & -w_{2} L_{m} & 0 & p L_{m}
\end{array} \\
& \begin{array}{cccc}
R_{r}+R+p L_{r} & R & 0 & 0
\end{array} \\
& R \quad R_{r}+R+p L_{r} \quad 0 \quad 0 \\
& 0 \quad 0 \quad R_{r}+R+p L_{r} \quad R \\
& \begin{array}{llll}
0 & R & R_{r}+R+p L_{r}
\end{array} \\
& \times\left\|i_{s_{1} d} \quad i_{s_{2} d} \quad i_{s_{1} q} \quad i_{s_{2} q} \quad i_{r_{1} d} \quad i_{r_{2} d} \quad i_{r_{1} q} \quad i_{r_{2} q}\right\|^{\top} \text {. }
\end{aligned}
$$

\footnotetext{
${ }^{2}$ Angular characteristics is the classical way used to evaluate the synchronization capablity of ESh [1], [3-4], [6], [8] and [16]
} 
The mechanical equations for both can be given as

$$
\begin{aligned}
& J p w_{1}=\left(3 / 2\left(\Psi_{s_{1} d} i_{s_{1} q}-\Psi_{s_{1} q} i_{s_{1} d}\right)-T_{s_{1}}\right), \\
& J p w_{2}=\left(3 / 2\left(\Psi_{s_{2} d} i_{s_{2} q}-\Psi_{s_{2} q} i_{s_{2} d}\right)-T_{s_{2}}\right) .
\end{aligned}
$$

\section{RESULTS AND DISCUSION}

Relying on the model given above the following results were obtained. In Fig. 3 are shown angular characteristics $^{2}$ of ESH using the steady state torque formulas. The deference between the two characteristics (With SR -bold line and without -dashed line) attest that the ignorance of SR may lead to big mistakes in terms of synchronization evaluation.

Figure 4a presents speed responses when the loads are as different as 1 to $2(20 / 40 \mathrm{~nm})$. In the transient phase a struggling process is witnessed. As we approach a steady state both responses are merging together attesting a successful synchronization. While the speeds are the same in steady state, torques (Fig.4b) show clearly how they are different from each other.

\subsection{THE STATOR RESISTANCE INFLUENCE}

The same case of Fig. 4 now performed with SR increasing $(100 \%)$ is shown in Fig. 5. Figure 5a shows how such increasing has caused synchronization lose marked by the speeds divergence. The responses of torques are shown in Fig. 5b. Besides the synchronization lose torques are featured by important ripples.

\section{CONCLUSION}

The study has dealt with a steady state and dynamic analysis of ESh system thanks to the newly developed mathematical models. The importance of SR has been

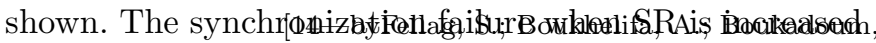
and its impact on the system components, speed and torques, has been clearly demonstrated using the transient model. The results show clearly how it is important to take into account $\mathrm{SR}$ resistances.

\section{DATA USED IN SIMULATION}

For simulation was used two motors having the following data: $L_{m}=0.092 \mathrm{H} ; L_{s}=0.094 \mathrm{H} ; L_{r}=0.094 \mathrm{H}$; $R_{s}=0.219 \mathrm{Ohm} ; R_{r}=0.211 \mathrm{Ohm} ; \quad R=0.7 \mathrm{Ohm} ;$ $J=0.09 \mathrm{Kgm}^{2} ; n_{0}=3000 \mathrm{~m}^{-1}, f=50 \mathrm{~Hz}$.

\section{REFERENCES}

[1] KOVACS, K. P.: Elektrische Welle in Reihenschaltung, Bull. Schweiz. elektrotechn. Ver. vol33 No. 16 (1942).

[2] KOVACS, K. P.-RACZ, I. : Transiente Vorgange in Wechselstrommaschinen, Verlag der Ungarischen Akademie der Wissenschaften, Budapest, 1959.
[3] UNGRUh, F.-JORDAN, G.: Systems of Rotation Concordance of Induction Electromotors (Sistemy soglasovanja vrashchenja asynkhronnykh elektrodvigatelei), Energia, 1971. (in Russian)

[4] USMANXODJAeV, N. M.-SAGITOV, P. I. Systems in Rotation Concordance of Induction Motors (Sistemy soglasovenja vrashchenii asynkhronykh dvigatelei): Elektrotexnika No. 2 (1976). (in Russian)

[5] SASTRY, K. R. P.-BURRIDGE, R. E.: Dynamics of a power synchro system with shunt- connected rotor resistances, IEEE Trasactions on power apparatus and systems, (1975).

[6] USManXodjaeV, N. M.-CAGitov, P. I.-BELOKOVSKI, P. I.: Teoriya i metodi rascheta sistem mnogodvigatelnovo asinchronovo electroprivoda (Theory and calculation methods of multiplemotor induction machines). Edition FAN 1989, Tashkent. (in Russian)

[7] GOKHBIRG, S. M. (Sinkhronyje rezhimy raboty trekhfaznykh induktivnykh mashin) Synchronic Functioning Regime of Three Phase Induction Machines: Elektrichestvo No. 6 (1925). (in Russian)

[8] CAGITOV, P. I: Razrabotka i islidovanie electromexanicheskix sistem soglassovannova vrashenia (Elaboration and investigation of electromechanical systems in rotation concordance), Dessertation on doctor of science, 1998, Almata. (in Russian)

[9] LEVI, E.-JONES, M.-VUKOSAVIC, S. N.: Even-phase multi-motor vector controlled drive with single inverter supply and series connection of Proceedings on Industrial Power Application, 2003 stator windings, IEE.

[10] DAMING, J. MA-WU, BIN-ZARGARI, N. R.-RIZZO, S. C.: A Space Vector Modulated CSI-Based AC Drive for Multimotor Applications, IEEE Transactions on Power Electronics 16 No. 4 (July 2001).

11] TURT, G.-SUMNER, M.-ASHER, G. M.: A synchronized multi-motor control system using sensorless induction motor drives power electronics and drives, IEE Conference Publication 2002.

[12] FRANCISCO, J. et al : Comparison of Multi-motor Synchronization Techniques, The 30-th Annual Conference of the IEEE Industrial Electronics Society, November 2-6,2004,Busan, Korea.

13] VALEnZuelA, A. M.-LORENZ, R. D. : Electronic Line-shafting Control for Paper Machine Drives, IEEE Transactions on Industry Applications 37 No. 1 (January/February 2001).

A.] The Dynamic Analysis of Electrical Shaft (ESh) fed from PWM Voltage Source and With common Capacity in Rotors'Circuit, PELINCEC 2005, Poland.

CHEE-MUNONG: Dynamic Simulation of Electrical Machinery, Prentice Hall PTR, 1998.

[16] FUENTES, R. : A static quasi electrical shaft for n-similar rotor winding induction motors, IEEE industry application conference record 2000, Rome, Italy.

Received 6 July 2009

Revised: 5 January 2010

Sid Ali Fellag, born in 1972 in Algeria, completed his school studies there. He received his master and PhD degrees from the technical university of Tashkent respectively in 1995 and 2000 , the $\mathrm{PhD}$ dissertation was on "The electromagnetic shaft system designed for long conveyors" under supervision of professor Usmankhodjaev: the inventor of electromagnetic shaft (a modified version of electrical shaft). From 2000 till now he has been a teacher (Associate Professor) at Tizi Ouzou university in Algeria. 